\title{
PSYCHOLOGICAL AND ENVIRONMENTAL STUDY OF WOMEN CRIMINALS.
}

II.

IT has been stated that the sociological factors are important. Though these are not entirely separable, and are so often closely interrelated with psychical conditions, what are some of the facts ascertained by the sociological investigation? The sources and methods included these: The former consisted in visits to the habitats of the criminals, an acquaintance with such facts as institution records show, possession of such observations as lay within the matrons' grasp, and an interrogation of the criminal and her associates. The method was: In the visits to the habitats sanitary and social surroundings, localities, habits, children, associates, condition of the homes, etc., were noted. From the records were made tables of the nationality, age, occupation, religion, conjugal condition, etc. Matrons usually furnish such facts as those relating to recidivism, condition of prisoners upon arrival, habits, conduct, industriousness, etc. The interrogation of the criminals and their associates is most frequently conducted in the laboratory, during the conversations while the tests are being taken, or are secured during seemingly chance conversations with the women in the prisons. It will be seen that these results are less accurate, less specific, and depend more upon what the criminal thinks and says. Thus they are lacking in the precision and definiteness of the psychological tests. It is precisely here that the value of the psychological tests may be seen, that is, in revealing the facts, or reasons for them. The sociological data are gathered from a much larger number of criminals, for they include those in the records, in the laboratory, and such as I could reach personally who were resident in the institution.

In presenting these results it becomes necessary here also to separate felonies from misdemeanors, the latter representing the workhouse type. Though these latter commit crimes 
less grave, they are more degenerate, and present the most hopeless aspect of the criminal problem. As in the psychological results, so in the sociological, the workhouse inmates show the greatest variation from normal or successful functioning and have a less advantageous environment.

The results obtainable from these sources and by these methods may be grouped under the following topics: nature of crime, age, nationality, religion, conjugal condition, number of children, occupation, education, habits, recidivism, degradation, moral sense, economic influence, parents and their occupation, industriousness, associates, disease, biological influences.

The question often arises: What crimes do women most frequently commit? During the summer months of 1899 there were incarcerated at Blackwell's Island (a typical workhouse) I,45 I prisoners, for the following offenses : disorderly conduct, 948 ; intoxication, 369 ; vagrancy, I22; petit larceny, I 2; disorderly house, 3. The crimes of the workhouse inmates are thus against public morals, public peace, and public policy. Out of 88 prisoners confined in the penitentiaries, I9 were for robbery, 28 for larceny, 17 for murder, 6 for manslaughter, I I for burglary, I for receiving stolen goods, 2 for forgery, 2 for assault, 2 for keeping girls, and I for conspiracy. Here the crimes are largely against property and public safety. The reasons for this are obvious: Women's crimes are more closely associated with immorality, because biologically she inclines to this rather than to crimes of force. In the penitentiaries, where robberies and larcenies are more numerous, the woman is often the accomplice in some disorderly house, or is a shoplifter or swindler in a gang with men. Where public safety is threatened, as in homicides, emotional conditions in woman, as contrasted with motives of gain in man, are often at work.

With reference to the age of women criminals almost nothing can be said. This depends entirely upon their statements, which are untrustworthy. While the workhouse contains young women, it is usually those whose habits of inebriety have rendered them incapable of securing a livelihood, even through an immoral calling. As a rule the women are older, and this does not include 
the paupers, who are usually old women, many of whom become intoxicated so they can be sentenced to the workhouse as a place of shelter. The penitentiary inmates are younger. This must necessarily be true, as their crimes require better vitality, more accurate thought, and quicker execution. Where I had an opportunity to learn the true age, I found the ages given me were always younger.

Records of institutions place stress upon nationality and upon religion. These seem of negative value as compared with some other facts. These records give the nationality, but whether foreign-born or where the parents were born is not stated. I found nationality to vary much with the locality ; and often, when tracing the line of descent, a half-dozen distinct nationalities were found. Few claimed "American," though the majority were American-born. The census shows that a greater percentage of women than of men are foreign-born, but my results included only one city where the influence of migration was great. Results in nationality, in order to be representative, must be extensive, and in ratio to the population of the nationality represented by the criminal class. Thus 24 Irish criminals out of a population of IOO Irish in a community would be a startling fact, but out of 5,000 , scarcely noteworthy. I consider the results of this observation of negative value in social study, unless the nativity of the parents, and the time spent by parents and criminals in America, are known. The social forces and their effect upon them are otherwise unascertainable.

The first objection to deductions from statistics upon religion is that it is closely related to nationality. Thus in an Irish or German community from which the criminal class comes the Catholic would predominate, and the rash deduction would be that more Catholics than Protestants were criminal. It is true, some religions represent a broader, more cultural plane, and where nationality can be eliminated statistics would prove valuable. What I did find of interest as bearing upon the cultural and educational side of the problem was the denominations represented in the Protestant religion. Thus out of 29 who claimed the Protestant religion II were Methodists, 7 Baptists, 5 Presbyterians, 
5 Episcopalians. ${ }^{x}$ This demonstrates from another point of view that emotional religions appeal more to this class than do the severer types, and are more suited to the desires and needs of the class from which the criminal comes. Religion has an important bearing upon the moral sense, which is considered later.

The conjugal condition presents an interesting phase, though not consistent in the various parts of the country. From 86 women in the penitentiaries visited, 50 were married. Out of 49 workhouse inmates measured, 35 were married and I I admitted divorce. The percentage of separations was also large. Many said they were not living with their husbands, though no legal decree had been sought. Of the I,45I women at Blackwell's Island workhouse, I,OI 2 were married. The reports of the Sherborn reform prison and of the Cincinnati workhouse show a contrary result. Numerically whether more married or unmarried women are criminals is not so much the important question as is the fact that so large a number of married women are found in prisons. Often these women are mothers. Where it was possible I ascertained the number of children. Among 44 married women recorded there were 48 children, and the 35 married women measured had 28 children. These figures vary with locality, but they show that forces stronger than a home and motherhood are in operation in sending women to penal institutions. Among these forces are: The marriage of many of these women does not withdraw them fully from the competitive world, for they must frequently contribute to the support of the family. If their lives have been previously immoral, and often when not so, they frequently marry men whose associates and habits continue, or induce their depravity. Association of ideas, the quality test, the number of separations and remarriages, and the conversations with some of the women reveal a high degree of domestic infelicity. These, together with the condition in which many of the women come to the workhouses, show a harshness of environment and a brutality of associates. This

${ }^{x}$ From the annual report of the Joliet penitentiary, where a record of the religions is kept, the Methodist and Baptist largely predominate. 
latter also applies to the unmarried women. A woman who marries lessens her opportunity for successful functioning in the industrial world: if she is secluded in the home, she has the keen edge of the competitive spirit, so essential to success, taken off; if there are children, she is handicapped physically and socially; there is a growing tendency to discriminate against married women, unless the appeal is made through sympathy rather than through capacity for labor.

Occupation, for many reasons, I consider important. Of the I,45 I at Blackwell's Island, I,298 were domestics, I 25 housekeepers (usually a doubtful occupation and closely related to courtesanship). The remainder were distributed among laundresses, laborers, seamstresses, dressmakers, cooks, peddlers, not any of these exceeding eight each and frequently including but one. The reports of other institutions show the same predominance of the domestic class. Besides showing that the domestic class furnishes the most criminals, it also shows a low degree of industriousness, for many become domestics only when all other shiftless means of securing a livelihood fail. An analysis of the domestic class, as found in cities, may suggest reasons :

This occupation offers the only solution of an economic problem to a large number of foreign women, to those who have no trade, and to those for whom no other field is open. It also includes many who, for mental or physical reasons, cannot earn a livelihood through any other means. This occupation includes those who enter it through choice, necessity, or by reason of limitations in their functioning capacity. The standard of the domestic class is necessarily fixed by the people within the group. The standard may not be that of every domestic within it, but there are common factors in each occupation. In the first place, there is a common grade of education. Some may be able to read and write, some may be illiterate, but there are common opinions, common points of view, and life is interpreted from a similar standpoint. There is a common moral standard. Some may be better, some worse, but the common standard is conditioned by the community of interests, degree of education, and kind of associates. It cannot be seriously questioned but 
that in the city occupation to a large extent determines one's associates. The class, as such, has similar temptations, and this tends to produce a similar moral status. They have similar opportunities. Some are greater, some are less; some are taken advantage of, some are not; but those remaining within the domestic class respond to these in a similar way. They enjoy similar amusements ; and here again, as through all social intercourse, the tastes and desires are influenced. For the following reasons, then, there is no occupation among women which includes so many criminals: ( $\mathrm{I}$ ) the large number of women in this occupation; (2) many of the lowest classes go into this occupation when other means fail; (3) inadequate salaries for the gratification of tastes in dress and amusements, which are developed through association (the domestic class is extremely social), and through leisure; (4) the easy route which this occupation furnishes to prostitution, through its temptations, almost all cases of prostitution resulting from seduction being from this class ; (5) the employment bureaus for servants, which are often but procuring places for prostitution; (6) the limited education and erroneous perception of the relation of things, especially true of the foreign class. Not a few immoral women ply their vocation under the guise of domestics. These are a few of the explanations which suggest themselves. Many of these reasons apply lower down in the scale, as to laundresses, scrub-women, etc. It is a notable fact that these women all claimed some occupation, showing a dependence upon their own efforts for subsistence. Almost all the occupations involve physical work, require a minimum mental expenditure, are accompanied by small salaries, and their tenure is dependent upon the whim or will of a single employer.

A number of the institutions have data regarding education, but I found these records most confusing. The great difficulty is that there is no standard educational test. The education was frequently designated by such phrases as "common school," "limited," "convent." There were no explanatory notes. It is unfortunate that no better educational test has been devised than the crude one of reading and writing. This test throws but little 
light upon our problem: How can the individual best function in society, and has she the requisites for so doing? An individual who can read and write can often adapt herself less readily to her environment, and if this is the test for education, it may well be said that the uneducated alone are not criminals. Experience and more accurate perception may not involve the ability to read and write, but may enable the individual to better adjust herself. Using this very inaccurate standard, out of 86 penitentiary inmates 35 claimed "common school," I 2 "read and write," I I "illiterate," 5 "convent," 22 "limited," I "high school." I found, when measuring the women, that "common school" might mean "six months in a country school," "two years in the public school," or "left at fifteen." I found that "limited" might mean barely able to form letters and read words, or that it might exceed the fluency of those registered "convent." "Illiterate" and "read and write" were more definite, but in the latter there were various degrees of proficiency, and no facts are ascertainable about the knowledge gained through experience and training. It is difficult to secure a definite statement, as the women generally desire to convey an impression of their superior intelligence. One subject insisted she had had mathematics, not arithmetic. After much parrying as to what specific part of mathematics she had, she finally named decimals, to which I responded : "Then, of course, you have had algebra?" to which she readily assented. This serves to demonstrate that education must be tested, and not the criminal's verbal assurance accepted. In my tests I learned the grade and reader in use when the subject left school. From such tests as those for memory, association of ideas, reading, respiration, etc., I was able to judge if their statements were true. These tests also showed the kind of spelling, proficiency in handwriting, capacity for attention and for memorizing, and rapidity of mental operation and association, which are criteria of education.

The penitentiary class is better educated than the workhouse class, but few of them rank out of the eighth grade or fifth reader, and most of them below this. Of the workhouse class this general statement is true: Though my tests required only the rudiments of education-reading and writing, and 
associating of ideas, and a fair degree of concentration - out of 400 women in the workhouse, deducting say 50 who would not come, I could secure only 20 who could give me satisfactory results. These 400 included nearly one hundred paupers, and I learned that but few of these could write. Again, out of these 400 women, with the privilege of writing home letters but once a month, only about one-sixth wrote letters, and one person often wrote for others. Of course, here such elements as short sentences, weak family ties (no one to whom they care to write), enter. I read I 32 of their letters, and found the spelling, composition, structure, and thought such as would entitle but very few to the title "educated." It is impossible to treat fairly or accurately the education or non-education of the criminal class with tests depending upon their verbal assertion.

Regarding the habits of criminal women, the records are again inaccurate. Here again the workhouse class is more degenerate and more frank about their habits. Out of 30 measured, I found 27 used alcohol, 7 chewed tobacco, 8 smoked, I 3 swore, I 5 used snuff, and fully seven-eighths were immoral. Probably the number using snuff is too small, as it is used as a substitute for alcohol and tobacco during incarceration. I found by inquiry among the matrons that these results were true for a much larger number. The results regarding immorality are secured from resident physicians. Disease through immorality, as reported by physicians, is not an absolutely trustworthy report where so large a percentage of the women are married. This element is eliminated in the reform-school statistics. Out of 108 girls ranging between the ages of ten and sixteen, 84 were immoral and 55 diseased. This percentage would increase with advanced age and increasing temptations and opportunities. Through such tests as hearing and smell my attention was called to the existence of catarrhal and scrofulous diseases. In general the workhouse women showed an impoverished condition of the system, and the hospitals were always filled with inmates awaiting surgical treatment.

Recidivism is the rule among the workhouse classes. This is true because their environmental conditions are more constantly 
unwholesome, and they have more degenerate habits which enthrall them. There is more abandon among this class. Supplementing the records I found in my tests that nearly two-thirds were recidivists. Some of them answered my queries regarding previous arrests thus: "Oh my, yes," "Of course," "Lots of times," "Sure." They often seemed surprised that I should find it necessary to ask. The penitentiary class are less frequently recidivists, are less frank, and often seemed insulted at the query and wept a negative reply.

It is a prevailing opinion that when women are criminal they are more degraded and more abandoned than men. From the observation of the two sexes, this seems due rather to the difference in the standards which we set for the two sexes. We say woman is worse, but we judge her so by comparison with the ideal of woman, not with a common ideal. For instance, I have included swearing and use of tobacco as bad habits among women; among men we should not consider them in the same light. These make a deeper impression by reason of the requirements of our ideal, not in the light of plain fact. Licentiousness in conversation and manner, uncleanliness in habits and person, do exist to a high degree; but the men and women come from the same classes, have the same standards, and know the same life. Thus from this point of view the woman is not more degraded than the man. Judged from the effect upon our ideals and upon society's life of, for instance, an intoxicated man or woman, the degradation seems more extreme.

Closely related to this is needed a word upon the moral sense of these women. Among the penitentiary class it is more intelligent, more wholesome. Granting that many are immoral because of perversity of instincts, because of desires, there is a large number for which deficient moral training is responsible. It is impossible to secure adequate moral training when the mental has not preceded it and opened the way for its comprehension. Here again the reform-school facts are most instructive. Many of the girls ranging between the ages of ten and sixteen have to be taught what morality means. A child born in or out of wedlock has for them the same meaning. It is not the theoretical 
teaching of morality which is needed, but a morality whose practical bearing upon every phase of life can be seen-one which shall quicken the moral sense in self-interest.

From the number of children in the criminal's family, combined with such knowledge of the financial condition as was obtainable, I attempted to gather some light upon the opportunities as a child. Out of $2 \mathrm{I}$ women, I 8 had brothers and sisters, the number varying from I 5 downward, the average being 5.5 for each. The occupation of the parents and wage rate furnish the financial data. I found several instances in which the criminal had deserted home when young. Among the common reasons were: "too much church," "too strict," self-willed," " desire for excitement," "to earn money," " ran away to marry." I also obtained data as to whether parents were living or dead, but as the age of the criminal when the parents died was so untrustworthy, I consider this valueless. It is, however, suggestive for other workers.

The number of children, together with the occupation of the parents, which was usually one of the trades or unskilled labor, and the early age at which many of them sought work, show that the opportunities for self-advancement must have been less than where good educations obtain.

The industriousness of these women furnishes another interesting condition. Out of I I 5 recorded, 60 admitted they were idle when the crime was committed. Matrons state that almost twothirds of the women are idle when arrested, and but few have trades. The cause is not always discernible. It may be due to inertia, to inability to secure work, to lack of interest in the only labor for which they are fitted, to a love of indolence and social life. Whatever the cause, it is a predisposing factor, giving the opportunity for crime which a busy life would not permit. Within the prisons the women show little disposition to work, but this must be true where labor possesses nothing to which the interest of the individual can respond-not even remuneration. Love of variety and excitement becomes a chronic desire, especially with the workhouse type, and this, with their habits, renders them incapable of sustained labor. 
That the economic conditions of woman render her liable to immorality has been so fully discussed elsewhere that I give only one illustration, the result of an investigation in New York. Clipping from the newspaper some thirty advertisements for clerks, stenographers, bookkeepers, etc., I had an assistant answer them. Although she visited only a little more than half the places, almost every one of them was a snare for immoral purposes, and the proposals were so bluntly made that she declined answering more. To a girl dependent upon herself in a large city an opportunity for immorality is thus offered in an attractive way. This is only one of a large number of temptations to immorality which come to women with economic independence.

A visit to the homes of the criminals verifies the above. The penitentiary class does not so uniformly come from the same district, so it is more difficult to trace out their homes. The workhouse class comes so uniformly from these "crime-breeding" districts that if a first offender from a new quarter comes in, they gather about her and say derisively: "Why, who be you?" "You must be innocent ;" "We don't know the likes of you." The districts have bad sanitary conditions, the houses are poor, ill-kept, and crowded, the quota of children being large. These districts are well supplied with places for social intercourse and for securing intoxicants. It is undoubtedly true that there are many criminals among the better classes and in more favorable districts, but they do not often find their way into the workhouses.

While presenting such factors as the preceding as distinguishing the workhouse and penitentiary type of criminal, no attempt is made to negative the biological side of crime, namely, the selfishness, greed for gain, luxurious tastes and lustful desires, need for excitement, elements of variety, jealousy, etc., which exist in the whole human race, and which predispose any or every individual to a species of crime.

At least the first step has been taken in the direction of the fulfillment of the three purposes of this investigation. Some differences between the senses and faculties of the criminal and the student have been noted. There remains much work here 
and in investigating the classes which are not criminal, but from which the criminals come. At various points throughout there have been suggestions of the way in which the psychological tests have suggested social factors or have supplemented the data secured through them. The ascertainment of a condition, such as defective hearing or taste, has stimulated inquiry which has revealed methods of living, habits, disease, etc., and almost all the tests have suggested the need of a more complete investigation. Association of ideas, the respiration curves, reading and hearing tests, and those for memory have thrown valuable light upon mental faculties and their operation; respiration tests sensibility to pain, precision and reaction time tests have been of great suggestive value in the emotional nature, which the criminal has so well developed. Thus psychology and sociology are indispensable in scientific research in criminality.

Psychology makes possible a quantitative sociology. This is a step in advance of statistical sociology. The psychological method applied to sociological data renders them more accurate, more definite. Two things are needed in a study of criminal sociology: such a presentation of facts as shall make possible a more rational, helpful attitude upon the part of the non-criminal class; legislation which shall be compelled to recognize these facts, and not revert to the precedents of the Middle Ages for its initiative. The needs are such as to press into the service of social investigation any science which renders it more trustworthy and liberal, and which relieves it from the charge of mere theorizing.

Frances A. Kellor.

The University of Chicago. 